\title{
Microstructure and Microhardness of Directionally Solidified Al-Si Alloys Subjected to an Equal-Channel Angular Pressing Process
}

\author{
Roberto Carlos Sales ${ }^{a}$, Leonardo de Olivé Ferreira ${ }^{b}$, Rangel de Paula Almeida ${ }^{\text {, Bráulio Pinto Terra }}{ }^{\text {, }}$ \\ Lucas Jardim de Moura ${ }^{a}$, Alexandre Furtado Ferreira ${ }^{a *}$ (D) \\ ${ }^{a}$ Universidade Federal Fluminense, Programa de Pós-Graduação em Engenharia Metalúrgica, \\ 27255-125, Volta Redonda, RJ, Brasil. \\ ${ }^{b}$ Universidade Federal do ABC, Grupo de Engenharia Aeroespacial, 98010-000, \\ São Bernardo do Campo, SP, Brasil.
}

Received: July 07, 2021; Revised: September 06, 2021; Accepted: October 08, 2021

\begin{abstract}
The directional solidification technique allows the study of growth of the solid phase, as-cast structure and, finally, its mechanical characteristics as a consequence of thermal parameters. On the other hand, in the last decade, a process called equal-channel angular pressing (ECAP) has emerged as a widely-known technique in fabrication of ultrafine-grained metals and alloys. Applicability of the ECAP technique affords an excellent potential for changing, in a controlled and beneficial manner, the resulting properties of metals and alloys. For this paper, an experimental research has been conducted to study the effects of solidification parameter (cooling rate) on resulting microhardness in hypoeutectic Al-Si alloys, upon use of an ECAP procedure. The influence of cooling on the scale of the dendritic patterns is presented and discussed with recourse to equations. The resulting microhardness variation with position throughout the as-cast materials and cooling rate were characterized by experimental power laws. Results determined after the solidification experiments have revealed microhardness as a function of both cooling rate and position $(\boldsymbol{P})$ of the as-cast materials to be dependent on alloy composition. In the ECAP process via route $\mathbf{C}$ with three passes, "as-solidified" microstructures have been found to be distorted and fragmented during the severe plastic deformation. This deformation imposed on the billets during the ECAP process facilitated obtaining a fine microstructure and high levels of microhardness were observed. However, even with the ECAP process, it was shown that microhardness is strongly dependent of the cooling rates.
\end{abstract}

Keywords: Equal-channel angular pressing, ultrafine-grained alloys, microhardness, solidification.

\section{Introduction}

Only in the last decades, experiments involving directional solidification with pure metals and their alloys have come into attention ${ }^{1-5}$. The mentioned technique allows a study of the growth of the solid and microstructure as a function of the solidification variables, making it a very attractive technique for investigation of these variables in solidification of metals and alloys ${ }^{6-18}$. When directional solidification is upward, the melt, rich in segregated solute, with a higher density as compared that the alloy melt, flows downward and the convection phenomenon is mostly confined between the dendrite arms, since the thermal gradient tends to stabilize density stratification in the melt. This may lead to dendritic fragmentation to accommodate high solute concentration in the interdendritic regions ${ }^{11}$.

Hypoeutectic ternary systems have been adopted by Baptista et al. ${ }^{11}$, Costa et al. ${ }^{12}$, Rocha et al. ${ }^{13}$ and Ferreira et al. ${ }^{14}$ with the purpose of studying the influence of thermal parameters on the microstructural development and microsegregation. Al-9 wt. \% Si-2 wt. \% Cu and Al-9 wt.\% $\mathrm{Si}-4$ wt.\% $\mathrm{Cu}$ alloys were unidirectionally solidified by

*e-mail: alexandrefurtado@id.uff.br
Baptista et al. ${ }^{11}$, with transient heat flow in a cooling range of 0.2 to $9{ }^{\circ} \mathrm{C} / \mathrm{sec}$. Experimental equations associating tertiary dendrite spacing with the thermal parameters were determined, showing that the increase in $\mathrm{Cu}$ content has induced an increase in dendrite arm spacing.

Recently, Sales et al. ${ }^{15}$ investigated the influence of thermal parameters on dendrite arm spacing and mechanical properties in Al-Si alloys directionally solidified. Characterization analyses indicated that there is an increase in dendritic arm spacing with the reduction in solidification speed and cooling rate during the solidification. Differently, experimental data obtained by Sales et al. ${ }^{15}$, have shown an increase in hardness as the solidification-process parameters are gradually increased.

Over the last ten years, a procedure has emerged for obtaining ultrafine-grained metals and alloys known as equal-channel angular pressing ${ }^{19-26}$. Basically, the ECAP technique consists in pushing a thick metal stick through a two directional matrix both of whose channels have identical cross sections intersecting at an angle $\phi$. They feature an additional angle $\mathbf{R}$, which defines the curvature of the intersection exterior to the channels. As the material progresses along the inside of the channels, it undergoes 
simple shearing-type plastic deformation, thereby being able to develop a new microstructure, with an also new crystallographic texture. The channel has two parts with equal cross-section on either side of the bend, which favors emergence of high shearing-strain specimens from the die and no changes on their cross-sectional dimensions. Therefore, the specimens of metals or alloys can be pressed repetitively through the die in order to attain exceptionally high strains.

García-Infanta et al. ${ }^{24}$ investigated a hypoeutectic Al-7 wt.\% Si alloy subjected to ECAP process up to eight passes via routes $A, B_{A}, B_{C}$ and $C$. No significant differences in tensile strength were found by authors, between the processed samples. However, there are differences in ductility of samples, which are attributed to the dependence of the fracture propagation path on the processing route due to different geometric redistribution of the eutectic region.

Microstructures resulting from ECAP process of Al-Si alloy by different processing routes were investigated by García-Infanta et al. ${ }^{25}$. In that experimental work, an Al-7 wt.\% $\mathrm{Si}$ alloy was subjected to ECAP using a $90^{\circ}$ die at room temperature for two different routes $\left(A\right.$ and $\left.\mathrm{B}_{\mathrm{C}}\right)$. The authors concluded that shapes changes of the microstructure mirror the straining for repetitive processing by these routes. Thus, the morphology and distribution of the eutectic constituent in processed samples reflect geometrical effects, although elongated $\mathrm{Si}$ and $\mathrm{Al}$ FeSi particles in the eutectic are also broken up. Grain refinement in the primary Al constituent is also strain-path dependent: grain subdivision combined with geometric effects is operative in samples processed by route $\mathrm{A}$, while grain subdivision alone predominates in samples processed via route $B_{C}$.

Swaminathan et al. ${ }^{26}$ have investigated the effects of the different ECAP processing routes on the microstructures and mechanical properties in a hypoeutectic Al-Si alloy. As-cast alloy billets were subjected to deformation by ECAP employing routes: $\mathrm{A}, \mathrm{B}_{\mathrm{A}}, \mathrm{B}_{\mathrm{C}}$ and $\mathrm{C}$. The observed microstructures suggest homogenization of the eutectic constituents via a progressive decrease in the widths of the primary Al dendritic cells, while straining results in microstructure resembling the as-cast microstructure with no homogenization after two and four passes in routes $\mathrm{C}$ and $\mathrm{B}_{\mathrm{C}}$, respectively.

Experiments were conducted by Duan et al. ${ }^{23}$ in order to evaluate the potential for producing some degree of homogeneity when processing by ECAP with a special split die having a channel angle of $90^{\circ}$. Using high-purity aluminum, measurements of the Vickers microhardness were recorded over cross-sectional planes after pressing through one to four passes. It was found that there is less homogeneity after one or two passes by comparison with conventional ECAP die. The results demonstrate a die with two equal arcs of curvature is less effective than a conventional ECAP die for producing homogeneity within the billets.

Over the years, regarding either vertical unidirectional solidification ${ }^{1-18,27-30}$ or equal-channel angular pressing ${ }^{19-26,31}$, ${ }^{32}$ experiments, sundry works have focused on the resulting microstructure. Since microstructure control is a key factor in generating excellent properties in metals and their alloys, determination of parameters which can affect said microstructures is of primary importance. It is in this general framework that the present work is elaborated, emphasizing the influence of cooling rates during vertical upward transient directional solidification on the "as-cast" microstructure and microhardness before and after equal-channel angular pressing of hypoeutectic Al-Si alloys.

\section{Materials and Methods}

Aflowchart of the experimental procedure for unidirectional solidification with processing by means of ECAP is given in Fig.1.

The variables show in Fig. 1, are defined as: $\lambda_{2}$ is secondary dendrite arm spacing $(\mu \mathrm{m}), \mathbf{S}_{\mathrm{s}}$ represents solidification speed $(\mathrm{mm} / \mathrm{s}), \dot{\mathbf{T}}$ is cooling rate $\left({ }^{\circ} \mathrm{C} / \mathrm{s}\right), \mathbf{L}_{\mathbf{S T}}$ is local solidification time (s), $\mathbf{H}_{\mathrm{v} 1}$ are of microhardness values $\left(\mathrm{H}_{\mathrm{v}}\right)$ before the ECAP process, $\mathbf{P}$ is position along the ingot $(\mathrm{mm})$ and finally the $\mathbf{H}_{\mathbf{V} 2}$ is microhardness obtained after ECAP process $(\mathrm{HV})$.

The experimental technique adopted for transient vertical upward directional solidification was previously described in greater detail in Refs. [1, 6, 11, 15]. The solidification apparatus which favors heat extraction from the bottom of the mold is depicted in Fig. 2.

The binary alloys used in our experiments were produced from aluminium $(99.9 \% \mathrm{Al})$ and silicon $(99.9 \% \mathrm{Si})$ in a muffle furnace. Their chemical composition was measured using fluorescence X-ray spectrometry. The molten alloys were poured into a mold for determination of the cooling curves during solidification experiments with an unsteadystate regime of heat extraction. The bottom part of the mold was closed with a thin $(3 \mathrm{~mm})$ carbon steel sheet. The initial temperature of the solidification apparatus and molten alloys were standardized at $740{ }^{\circ} \mathrm{C}$. Temperature mapping during our binary-alloy solidification experiments was carried out by recourse to thermocouples located at eight different points, positioned at $5,10,15,20,35,45,60$ and $85 \mathrm{~mm}$

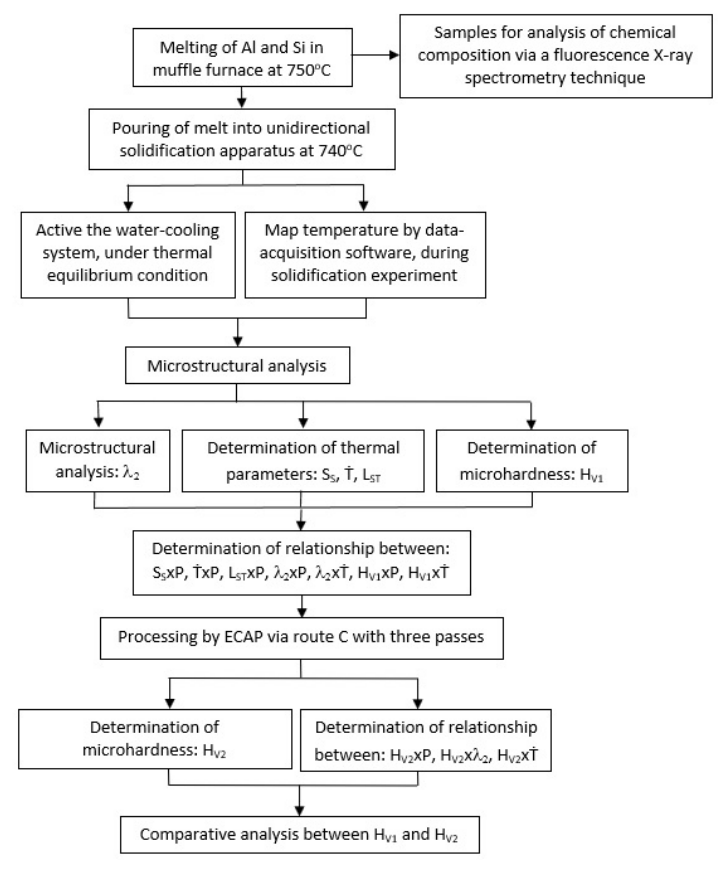

Figure 1. Flowchart of the experiments. 
from the refrigerated base. It is important to highlight those thermocouples maintained their initial position during the solidification experiments. These thermocouples were connected to a high-speed data logger and, therefore, able to generate real-time thermal profiles. Temperature data were sampled at 0.01 seconds intervals by a data-logging interface and stored in a personal computer.

Cooling rates can be determined from temperature and time values recorded after the passing of the liquidus front by each thermocouple. Transverse specimens were cut from positions close to each thermocouple tip, with the purpose of obtaining a relationship between solidification parameters, dendrite-arm spacing, and microhardness. The specimens were polished with abrasive paper and then etched with a solution of $0.5 \% \mathrm{HF}$, for further microstructural analysis ${ }^{11,15}$.

An Olympus Optical Microscope (Olympus Corporation, Japan) was used to produce digital images that were analyzed using the Goitaca (https://sourceforge.net/projects/goitacaeq) image processing software in order to measure the dendritic spacings. Dendritic spacing usually refers to the space between primary arms of the dendrites. However, if secondary arms are present, the spacing will be referred to as their smaller dimensions become more significant for the properties of the material, as discussed by Paradela et al. ${ }^{29}$. For each specimen, secondary-dendrite spacings were determined by averaging the distance between adjacent side branches. The average dendritic arm spacings were determined from about 40-45 measurements for each examined position along the entire die-casting. The secondary dendrite arm spacing $\left(\lambda_{2}\right)$ was measured on the transverse sections of each sample by using the linear intercept method ${ }^{8,11,15}$. Microhardness tests was performed in at least twelve different positions on the transverse section. A loading time of 15 seconds, as well as load of $100 \mathrm{~g}$, were used in a Vickers pyramidal indenter.

Transverse specimens were cut from the castings and prepared for equal channel angular pressing (ECAP). A schematic to illustrate the obtention of the billets from the directionally solidified ingots is given in Fig. 3.

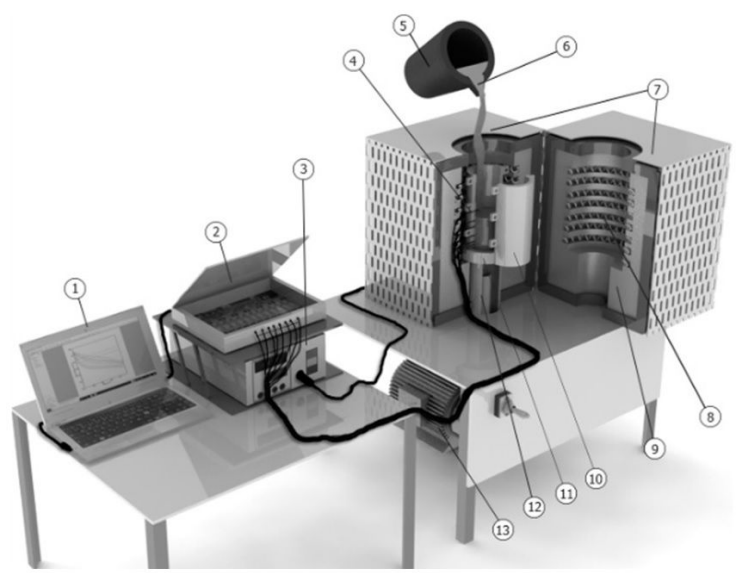

Figure 2. Diagrammatic representation of equipment: (1) personal computer and data-acquisition software; (2) data-logging hardware; (3) temperature-control system; (4) K thermocouples; (5) crucible; (6) melt; (7) unidirectional solidification furnace; (8) electric heaters; (9) ceramic fiber insulation; (10) steel mold; (11) steel plate; (12) water-cooled bottom; (13) water pump (Ferreira et al. ${ }^{27}$ ).
Aluminium alloys used in this investigation were pressed using an experimental facility for ECAP installed in the Laboratory of Mechanical Tests of the Federal Fluminense University, Fig. 4a.

The ECAP was conducted mostly at room temperature, on an EMIC-600 universal testing machine equipped with a $600 \mathrm{kN}$ load cell and die that have an internal $90^{\circ}$ angle between two parts of the channel and outer arc of curvature of some $37^{\circ}$, where the two parts intersect. The ECAP die required use of billets with $60 \mathrm{~mm}$ in length and square cross section of $10 \mathrm{~mm} \times 10 \mathrm{~mm}$. The speed of the plunger was $5 \mathrm{~mm} / \mathrm{min}$. The processing route used in our experiments was route $\mathrm{C}$, with three passes. In the case of processing by Route $\mathrm{C}$ (rotations of $180^{\circ}$ and three passes), the microstructures resulting from ECAP process, are similar to that of the ascast microstructure and consist of equiaxed primary dendritic cells, according to Swaminathan et al. ${ }^{26}$. The specimens were rotated by $180^{\circ}$ around the vertical direction between passes, as depicted in Fig. 4c. Repetitive pressing provides a choice opportunity of different slip systems on each consecutive pass by simply rotating the specimens in different ways,



Figure 3. Schematic to illustrate the obtention of the billets from the solidified ingots.

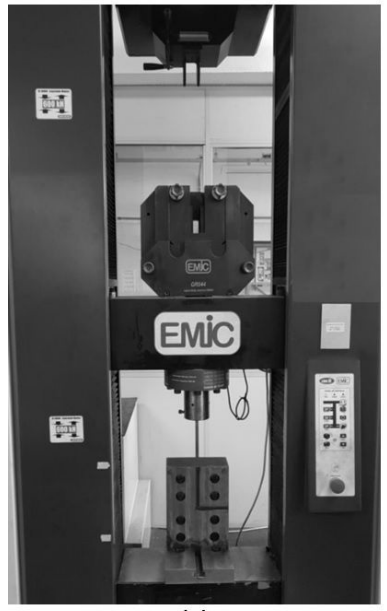

(a)

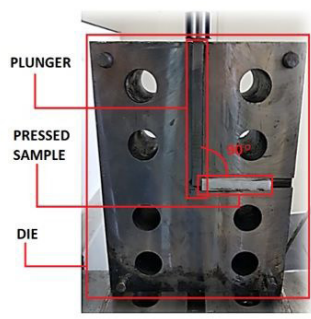

(b)

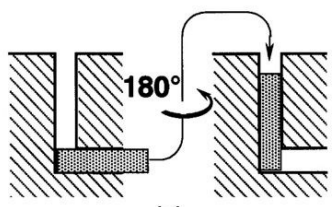

(c)
Figure 4. Equal-channel angular pressing (ECAP): a) Adaptation of the universal testing machine EMIC- 600 for pressing via ECAP, b) Parts of ECAP with pressed sample and c) Schematic representation of route $\mathbf{C}$ with three passes. 
Nakashima et al. ${ }^{31}$ The distinction between these routes and the difference in number of ECAP passes may lead to variations both in the macroscopic distortions of the grains and in the capability to develop a reasonably homogeneous and equiaxed ultrafine-grained microstructure, Furukawa et al. ${ }^{32}$

\section{Results and Discussion}

The present work is divided into two parts. The first part is focused on solidification analysis of $\mathrm{Al}-3 \mathrm{wt} . \% \mathrm{Si}$ and $\mathrm{Al}$ - 7 wt. \% Si alloys, and second part deals with analysis of the as-cast alloys after ECAP process.

\subsection{Solidification analysis of Al - 3 wt. \% Si and Al - 7 wt. \% Si alloys}

Figure 5 exhibits the phase diagram of the system of alloys investigated, computed with help of a well-known thermodynamics software package ${ }^{33}$.

For aluminum alloys with 3 wt. \% Si and 7 wt. \% Si, during cooling the solidification process is started with liquidus temperature of $642^{\circ} \mathrm{C}$ and $615^{\circ} \mathrm{C}$, respectively, as shown in Fig. 5, emphasizing the liquid-solid transformation region. In that figure, both hypereutectic and hypoeutectic regions are displayed and the limit of silicon solubility in the solid phase is in evidence at $1.6 \mathrm{wt}$. \% $\mathrm{Si}$ at a given temperature of $577^{\circ} \mathrm{C}$. On the other hand, Figs. $6 \mathrm{a}$ and $6 \mathrm{~b}$ exhibit the cooling profiles obtained in the course of our solidification experiments.

As evinced in Figs. 6a and 6b, temperature profiles quickly decrease at positions close to the mold base and then moderately decrease in the direction of solidification completion. One of the thermocouples was placed $5 \mathrm{~mm}$ from the mold base and the others were positioned at 10, 15, 20,

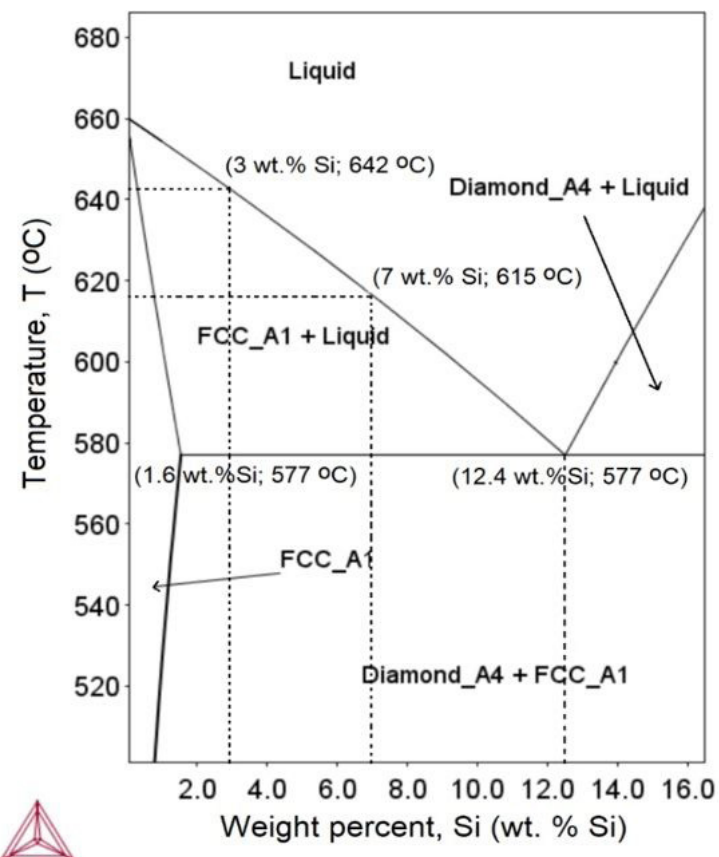

Figure 5. Phase diagram of Al-Si system as computed with the Thermo-Calc Software ${ }^{33}$ with Aluminum Database v4.0.
35, 45, 60 and $85 \mathrm{~mm}$ away from the base. These cooling profiles are similar to those found by Baptista et al. ${ }^{11}$ and Paradela et al. ${ }^{29}$, showing small plateaux close to liquidus temperature. The pouring temperatures were set up at about $740{ }^{\circ} \mathrm{C}$, in both cases.

The thermal parameters, such as $\boldsymbol{S}_{S}$ and $\dot{\boldsymbol{T}}$, were determined from the cooling profiles (Figs. $6 \mathrm{a}$ and $6 \mathrm{~b}$ ) measured by a high-speed data logger. The $S_{S}$ is experimentally calculated as $\boldsymbol{S}_{\boldsymbol{S}}=\boldsymbol{d P} / \boldsymbol{d} \boldsymbol{t}$, as suggested by Paradela et al. ${ }^{29}$ The cooling rate, on the other hand, is determined, for each position of the thermocouples, as $\dot{\boldsymbol{T}}=\boldsymbol{D T} / \boldsymbol{d t}$, consistent with both Baptista et al. ${ }^{11}$ and Sales et al. ${ }^{15}$ Through the cooling profiles, the position of the liquidus temperature $\left(T_{L}=642^{\circ} \mathrm{C}\right.$ and $\boldsymbol{T}_{L}=615^{\circ} \mathrm{C}$ ) was determined as a function of time by regression of the experimental data, as depicted in Figs. 7a and $7 \mathrm{~b}$.

From this function $(\boldsymbol{P}=\boldsymbol{f}(\boldsymbol{t}))$, the value of $\boldsymbol{S}_{\boldsymbol{S}}$ was determined as a function of the time by computing the time derivative of $\boldsymbol{P}$. Figures $7 \mathrm{a}$ and $7 \mathrm{~b}$ display these results, also. Regrouping both equations $\left(P=f(t)\right.$ and $\left.S_{S}=f(t)\right)$, an equation of $S_{S}$ positiondependent, can be found, as depicted in Fig. 8, where $\boldsymbol{S}_{S}$ is plotted against $\boldsymbol{P}$.

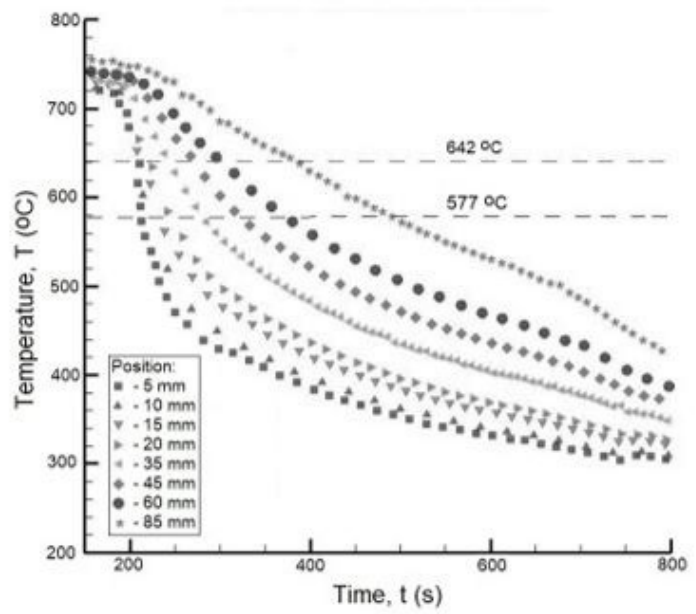

(a)

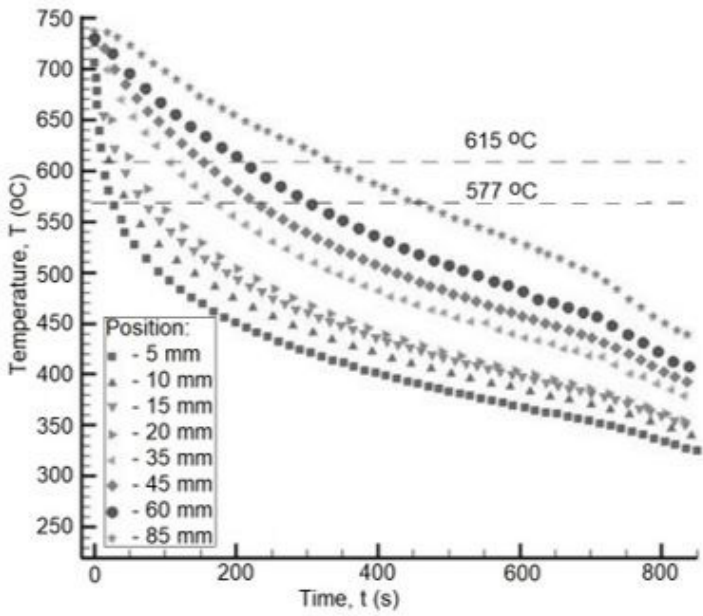

(b)

Figure 6. Temperature profiles for each position of the thermocouples: a) $\mathrm{Al}$ - 3 wt. \% Si alloy, and b) Al - 7 wt. \% Si alloy. 


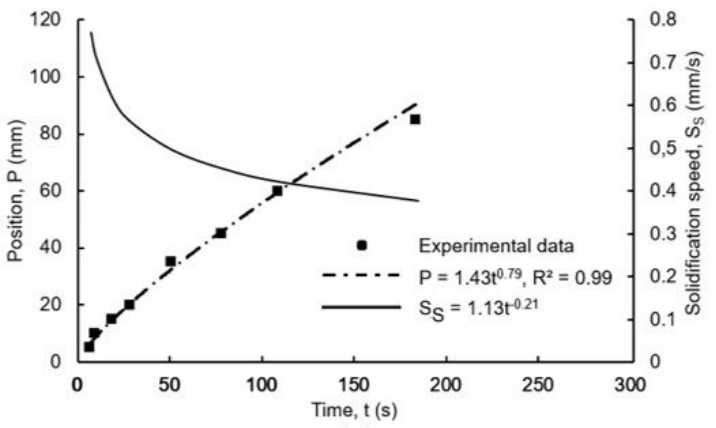

(a)

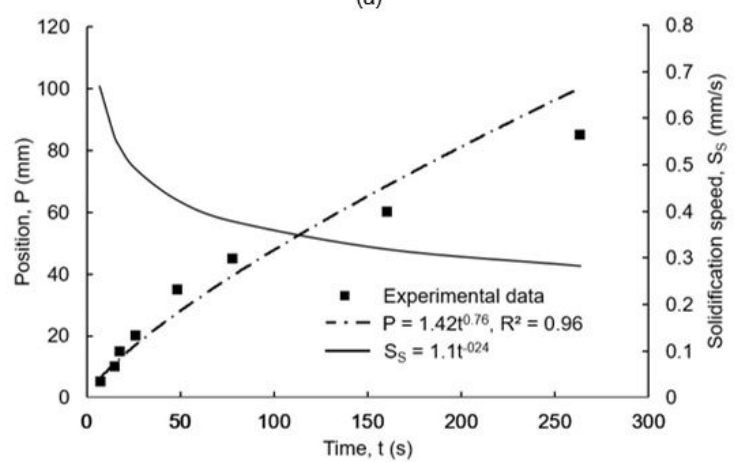

(b)

Figure 7. Liquidus temperature position and solidification speed $\left(\boldsymbol{S}_{S}\right)$ versus time: a) Al - 3 wt. \% Si alloy, and b) Al - 7 wt. \% Si alloy.

In both cases, the $\boldsymbol{S}_{S}$ curve decreases faster in the positions close to the cooling base and becomes almost constant as one moves away from the base. This stems from the fact that the water-cooling system favors high $S_{S}$ in positions close to the mold bottom. On the other hand, the value of $S_{S}$ decreases along the casting, due to an increase in thermal resistance in the solidified region. We can see in Fig. 8 a slight discrepancy between the experimental profiles. The results suggest that the silicon addition to the aluminum alloy lead to a decrease in $\boldsymbol{S}_{s}$. Analyzing the discrepancy between profiles, at the $5 \mathrm{~mm}$ position the $S_{S}$ found in the experiment with the Al-7 wt.\% Si alloy is $11 \%$ lower than the speed found for the one with the Al-3 wt.\% Si alloy, while at the $85 \mathrm{~mm}$ position this value is increased by about $25 \%$. Experiments of solidification with water-cooled molds are very useful when high cooling rates are desired. Higher cooling rates yield rapid solidification, i.e., a short solidification time, which can affect beneficially the morphology of microstructure, such as grain size and dendritic spacing.

Cooling rate $(\dot{\boldsymbol{T}})$ versus position $(\boldsymbol{P})$ is displayed in Fig. 9. Once again, we can see a discrepancy in the experimental profiles, which indicates that the cooling rates are significantly influenced by changes in solute concentration, while preserving the same profiles along the casting length for both cases analyzed. Similar profiles were found by Baptista et al. ${ }^{11}$ and Sales et al. ${ }^{15}$. The $\dot{\boldsymbol{T}}$ and solute concentration are factors acting in parallel with $S_{S}$ during the solidification experiments, which servers to condition the changes in structure and mechanical properties in ascast materials.

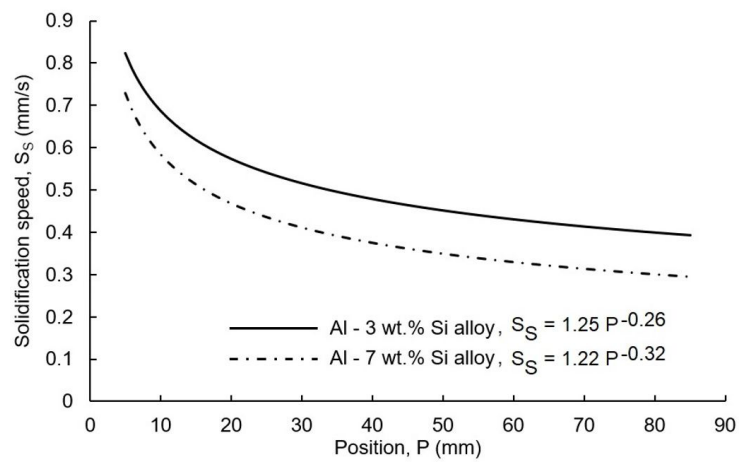

Figure 8. Solidification speed $\left(\boldsymbol{S}_{S}\right)$ versus position $(\boldsymbol{P})$.



Figure 9. Cooling rate $(\dot{\boldsymbol{T}})$ versus position $(\boldsymbol{P})$.

As the solidification proceeds, a continuous increase of the local solidification time in different positions along the castings was observed, Fig. 10. One can see that the $\mathbf{L}_{\mathrm{st}}$ profile moves upward, with an increase in solute concentration, from 3 to 7 wt.\% Si. Deviations between the solidification times arise because the solute concentration exerts an effect on $\boldsymbol{S}_{s}$ and this parameter, in turn, can affect the local solidification time during solidification experiments. Comparative analysis of the profiles of the local solidification time and $\boldsymbol{S}_{S}$ versus $\boldsymbol{P}$, reveal that $\boldsymbol{S}_{S}$ dwindles quickly at the region close to the mold bottom, followed by a gradual, slower decrease along castings. In contrast, an inverse trend can be observed in the local solidification times close to the bottom, $\mathbf{L}_{\mathbf{s t}}$ increases faster; afterwards, it starts a gradual increase along castings. Higher $\boldsymbol{S}_{S}$ favors rapid solidification, i.e., a short local solidification time. It is worth mentioning that as-cast alloys with wide solidification intervals make them susceptible to segregation phenomena during the procedure.

Secondary dendrite arm spacings $\left(\lambda_{2}\right)$ for different $\boldsymbol{P}$ and $\dot{T}$ are shown in Figs. 11a and 11b. The profiles depicted in Fig.11a correspond to experimental functions obtained from experimental data for alloys considered in our experiments. The focal point of these experimental results was $\lambda_{2}$, which increases with $\mathbf{P}$ in the course of the castings. However, increasing the silicon concentration (from $3 \mathrm{wt} . \%$ to $7 \mathrm{wt} . \%$ $\mathrm{Si}$ ), changes in $\lambda_{2}$ can be observed. The next two profiles in Fig. $11 \mathrm{~b}$ correspond to $\lambda_{2}$ as a function of $\dot{\boldsymbol{T}}$. In that figure, the dashed curves come from experimental functions that were fitted to the experimental data. As can be seen, in both cases $\lambda_{2}$ is affected by $\dot{T}$, which is evidenced by the 




Figure 10. Local solidification time $\left(\boldsymbol{L}_{s t}\right)$ and solidification speed $\left(\boldsymbol{S}_{S}\right)$ versus position $(\boldsymbol{P})$.



(a)

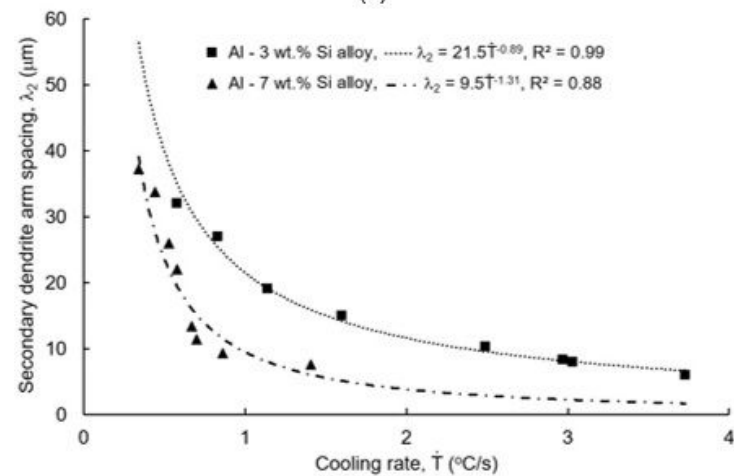

(b)

Figure 11. Secondary dendrite arm spacing $\left(\lambda_{2}\right)$ versus: a) position (P) along the castings, and b) cooling rate ( $\dot{\mathbf{T}})$.

experimental expressions. The profiles are in agreement with the published literature (Baptista et al. ${ }^{1}$, Sá et al. ${ }^{34}$ and Carvalho et al. ${ }^{35}$ ) and show the effect of $\dot{\boldsymbol{T}}$ on $\lambda_{2}$. This effect translates to the microstructure growth, i.e., high values of $\dot{T}$ near the mold bottom favor a more refined microstructure, whereas low values of this thermal parameter close to the top of the castings contribute effectively to yield a coarser microstructure.

The Vickers microhardness $\left(\boldsymbol{H}_{V}\right)$ with load of $100 \mathrm{~g}$, was also measured at all monitored points, after the solidification experiments. The $\boldsymbol{H}_{V}$ profiles through the castings are shown in Fig. $12 \mathrm{a}$, where a variation of $\boldsymbol{H}_{\boldsymbol{V}}$ values with the positions of casting can be observed. As expected, in positions near

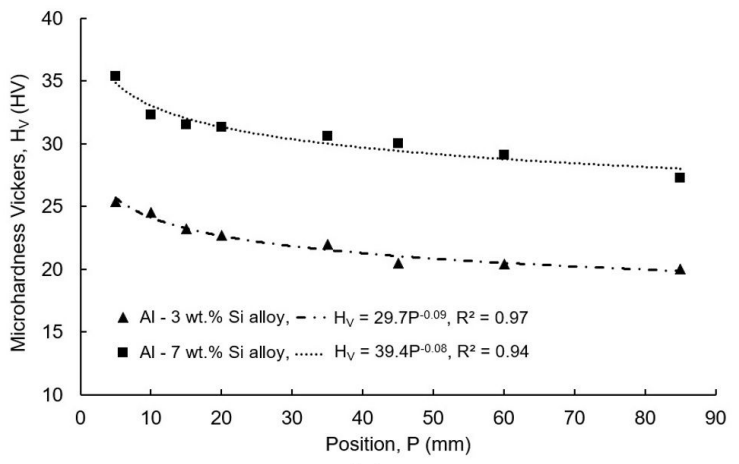

(a)

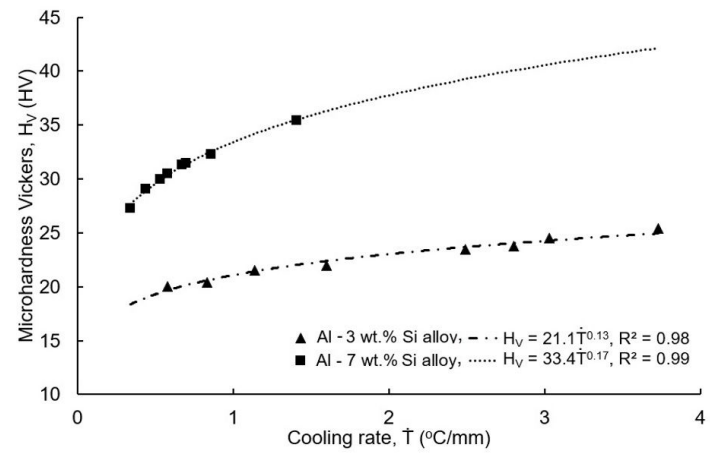

(b)

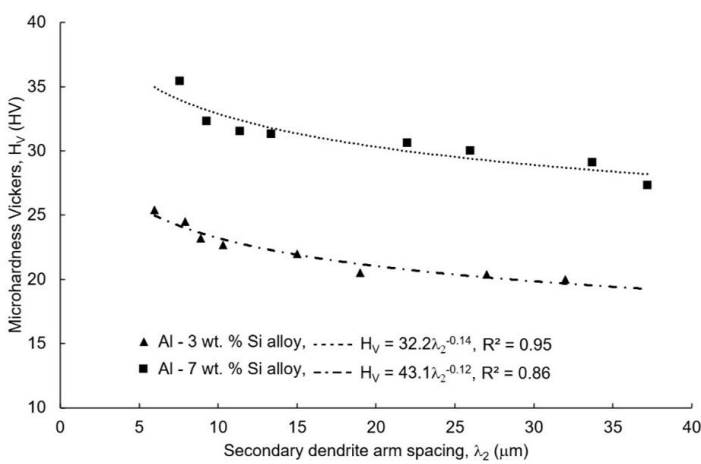

(c)

Figure 12. Microhardness Vickers versus: a) Position $(\boldsymbol{P})$ along the castings, b) Cooling rate $(\dot{\boldsymbol{T}})$, and c) Secondary dendrite arm spacing $\left(\lambda_{2}\right)$.

the cooling plate, an improvement in $\boldsymbol{H}_{\boldsymbol{V}}$ is observed, due to the fine microstructure as a consequence of high values of $\dot{\boldsymbol{T}}$ and $\boldsymbol{S}_{\boldsymbol{s}}$. These results $\left(\boldsymbol{H}_{\boldsymbol{v}}\right.$ versus $\boldsymbol{P}$ and $\left.\dot{\boldsymbol{T}}\right)$ are similar to those presented by Sales et al. ${ }^{15}$ and Paradela et al. ${ }^{29}$. As shown in Fig. 12a, for Al - 3 wt.\% Si and Al - 7 wt.\% Si alloys, the $\boldsymbol{H}_{\boldsymbol{V}}$ decreased from 25.4 to $20.1 \mathrm{HV}$ and from 35.4 to $27.3 \mathrm{HV}$, which confirms a reduction of about $21 \%$ and $23 \%$ along the castings, respectively. However, with an increase of solute concentration from 3 to 7 wt.\% Si, alloy average $\boldsymbol{H}_{\boldsymbol{V}}$ is increased from 22 to $31 \mathrm{HV}$, which shows a remarkable increase of about $29 \%$. One can see in Fig. $12 \mathrm{~b}$ that $\boldsymbol{H}_{\boldsymbol{V}}$ is affected by microstructure resulting from $\dot{\boldsymbol{T}}$, which is evinced by two experimental functions, $H_{V}=21.1 \dot{T}^{0.13}$ and $H_{V}=33.4 \dot{T}^{0.17}$. 
Higher cooling rates $(\boldsymbol{T})$ are responsible for a decrease in secondary dendritic arm spacing $\left(\lambda_{2}\right)$ and this parameter, in turn, favor an improvement in resulting microhardness at regions close to the cooling plate. Mechanical properties of as-cast alloys are strongly connected to their microstructures obtained after solidification. The effect $\dot{\boldsymbol{T}}$ has on the mechanical properties manifests itself by engendering a variety of microstructures with different morphologies and sizes. Higher $\dot{\boldsymbol{T}}$ leads to a reduction of microstructure and formation of as-cast alloys with high strength and hardness, because it suppresses atomic diffusion during solidification, Paradela et al. ${ }^{29}$.

\subsection{Analysis of the As-cast Alloys after ECAP process}

Figure 13 depicted the as-cast microstructure of an Al 7 wt.\% Si alloy before and after an operation of equal-channel angular pressing. One can see in Figs.13a through $13 \mathrm{c}$ that a dendritic-type microstructure prevailed along the entire casting. Below each micrograph information can be found concerning the position $(\mathbf{P})$ from where the specimens were

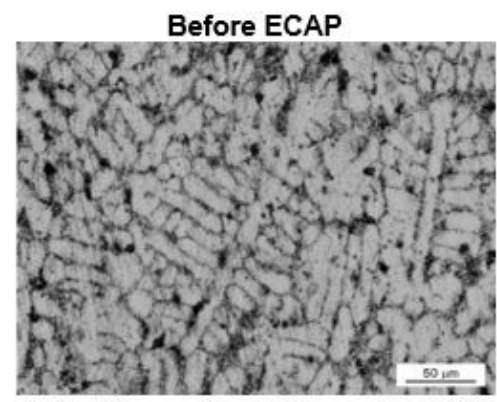

a) $P=35 \mathrm{~mm}, \lambda_{2}=22.1 \mu \mathrm{m}, S_{s}=0.39$ $\mathrm{mm} / \mathrm{s}, \dot{\mathrm{T}}=0.58^{\circ} \mathrm{C}$ and $\mathrm{Hv}=30.6 \mathrm{HV}$

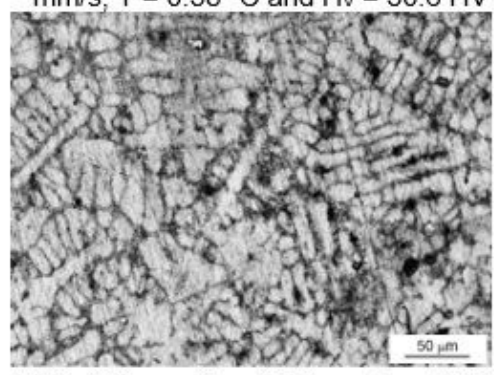

b) $\mathrm{P}=60 \mathrm{~mm}, \lambda_{2}=33.7 \mu \mathrm{m}, \mathrm{s}_{\mathrm{s}}=0.33$ $\mathrm{mm} / \mathrm{s}, \dot{\mathrm{T}}=0.44^{\circ} \mathrm{C}$ and $\mathrm{Hv}=29.1 \mathrm{HV}$

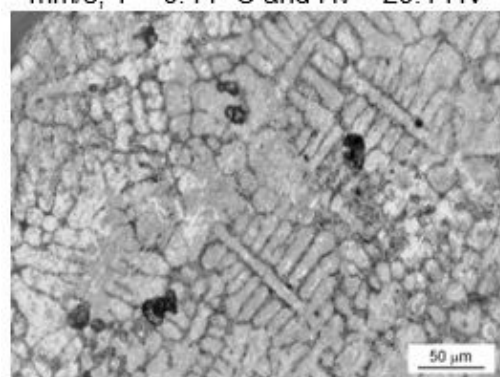

c) $\mathrm{P}=85 \mathrm{~mm}, \lambda_{2}=37.2 \mu \mathrm{m}, \mathrm{S}_{\mathrm{s}}=0.29$ $\mathrm{mm} / \mathrm{s}, \dot{\mathrm{T}}=0.34^{\circ} \mathrm{C}$ and $\mathrm{Hv}=27.3 \mathrm{HV}$ extracted in the casting, values of $\lambda_{2}, \mathbf{S}_{\mathrm{s}}, \dot{\mathbf{T}}$ and microhardness $\left(\boldsymbol{H}_{V}\right)$. On the other hand, Figs. 13d through 13e display the cast microstructure of our Al - 7 wt.\% Si alloy after ECAP with three passes via route $\mathbf{C}$.

As can be seen from these pictures, dendritic microstructures have distorted and fragmented morphology because of the imposed deformation. Figs. 13d through 13e also show the changes in $\boldsymbol{H}_{\boldsymbol{V}}$ in deformed specimens. It is clear from these images that the $\boldsymbol{H}_{\boldsymbol{V}}$ of any specimen considered increased after ECAP. This is a consequence of work hardening during ECAP of the as-cast alloy. In addition, the ECAP process using route $\mathbf{C}$ with three passes is recognized to favor material hardness. Using ECAP with a high number of passes, the breakdown of dendrites is more intensive and the size of these broken microstructures is finer, therefore the microhardness is increased in comparison to simply as-cast alloys. It is worth mentioning that, as a result of applied ECAP in the billets, the eutectic Si fibers are fragmented, dispersed and spheroidized in the matrix. This microstructural evolution favors higher mechanical properties, such as microhardness, as discussed by Haghshenas et al. ${ }^{36}$. The microhardness of all previously mentioned specimens from our Al - 3 wt.\%

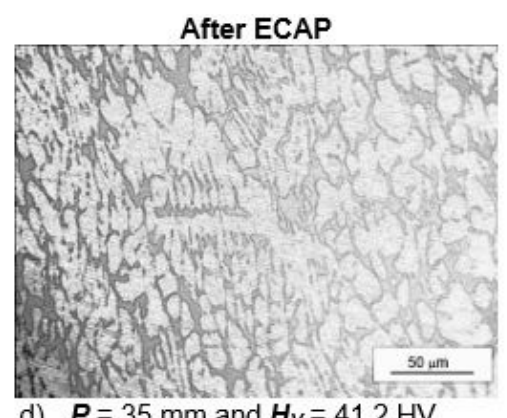

d) $P=35 \mathrm{~mm}$ and $\boldsymbol{H}_{V}=41.2 \mathrm{HV}$

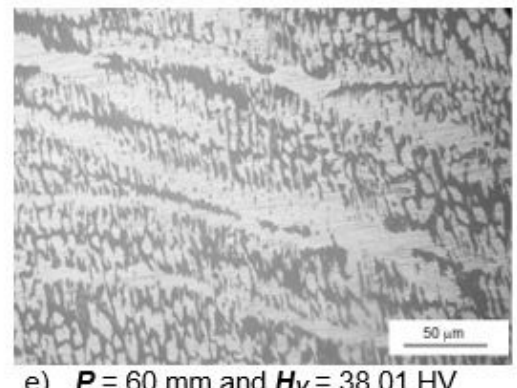

e) $P=60 \mathrm{~mm}$ and $H_{V}=38.01 \mathrm{HV}$

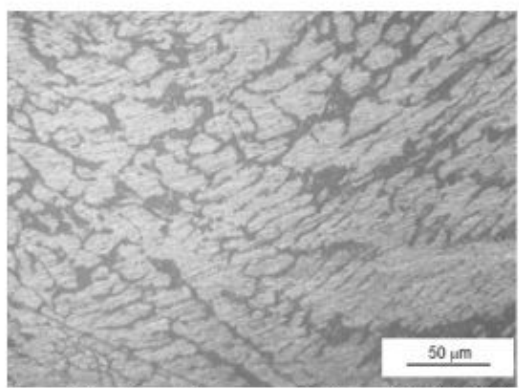

f) $P=85 \mathrm{~mm}$ and $H_{V}=37.78 \mathrm{HV}$

Figure 13. Dendritic microstructure of an $\mathrm{Al}-7 \mathrm{wt} . \% \mathrm{Si}$ alloy before and after an operation of equal-channel angular pressing. 


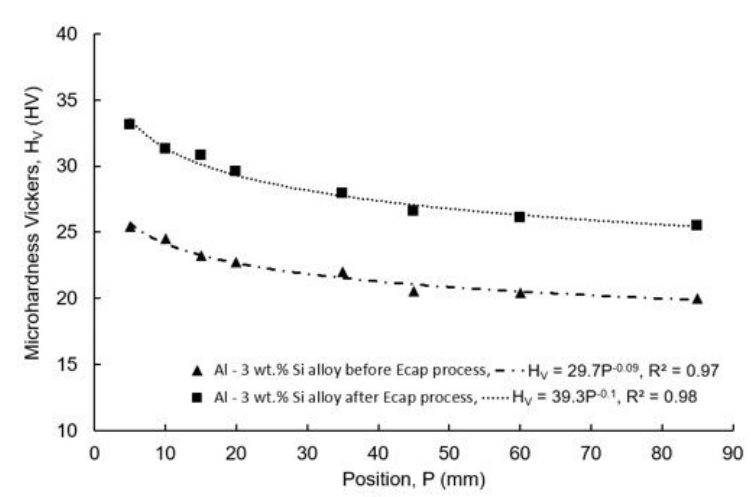

(a)

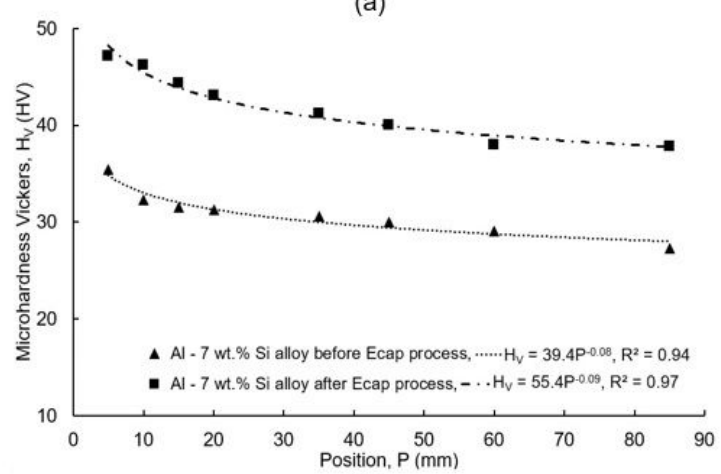

(b)

Figure 14. Measurements of microhardness before-after ECAP process: a) $\mathrm{Al}-3 \mathrm{wt} . \% \mathrm{Si}$ alloy, and b) $\mathrm{Al}-7 \mathrm{wt} . \% \mathrm{Si}$ alloy.

Si and Al - 7 wt.\% Si alloys (Fig. 12a), were compared with those obtained after application of ECAP.

Figs. $14 \mathrm{a}$ and $14 \mathrm{~b}$ display the microhardness along the casting length, before and after ECAP.

It should be mentioned that the billets did not suffers significant deformation on its longitudinal section after ECAP process. Similar profiles have been observed for all the alloys examined, even after ECAP. It deserves highlight that in $\mathrm{Al}-3 \mathrm{wt} . \% \mathrm{Si}$ and $\mathrm{Al}-7 \mathrm{wt} . \%$ alloys, the microhardness after ECAP with three passes increased its average values from $22 \mathrm{HV}$ (before ECAP) to $29 \mathrm{HV}$ (after ECAP) and from $31 \mathrm{HV}$ (before ECAP) to $42 \mathrm{HV}$ (after ECAP), respectively. Through an analysis of these experimental data, it can be concluded that after ECAP, the Al - 3 wt.\% Si alloy had its average microhardness increased by about $24 \%$, while the $\mathrm{Al}-7 \mathrm{wt} . \% \mathrm{Si}$ alloy shows an increase of $26 \%$. We can see that the three-pass ECAP process had a greater effect on the microhardness of $\mathrm{Al}-7 \mathrm{wt} . \% \mathrm{Si}$ alloy than on the microhardness of the Al - 3 wt.\% Si one. This finding can be attributed to the fact that in Al - 7 wt.\% Si alloy case, a more intense grain refinement is achieved by ECAP process when compared to the Al - 3 wt.\% Si alloy. Even after the ECAP process with three passes via route $\mathbf{C}$, the microhardness profiles for both alloys are clearly nonlinear, with both curves roughly asymptotic to the horizontal axis of the plot.

As the results for microhardness suggest, even after ECAP, which is one of the most commonly employed severedeformation processes to drive ultrafine-grained microstructure, the cooling rates $(\dot{\boldsymbol{T}})$ through initial microstructure, still exerts

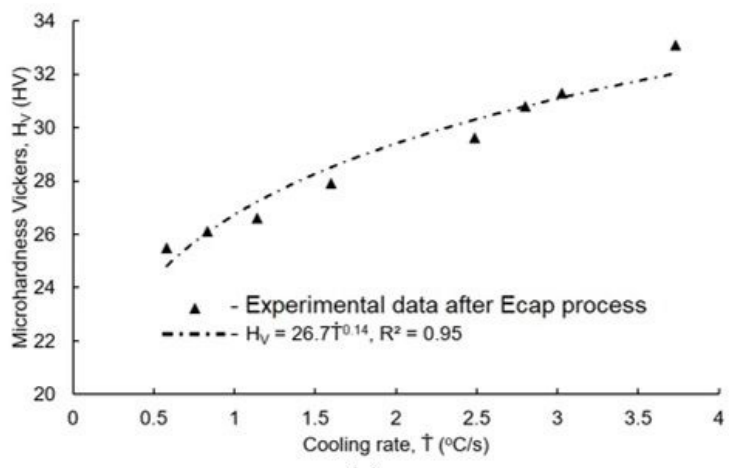

(a)

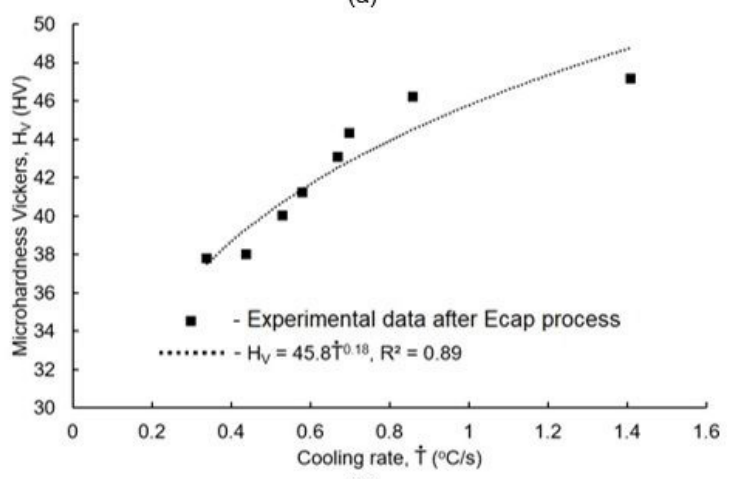

(b)

Figure 15. Measurements of microhardness $\left(\boldsymbol{H}_{V}\right)$ after ECAP versus cooling rate ( $\dot{\boldsymbol{T}})$ : a) $\mathrm{Al}-3 \mathrm{wt} . \% \mathrm{Si}$ alloy, and b) $\mathrm{Al}-7 \mathrm{wt} . \% \mathrm{Si}$ alloy.

a strong effect on the mechanical properties of the as-cast material, as depicted in Figs. 15a and 15b.

Microhardness dependence on the cooling rate can be observed in those pictures, where variations of this mechanical property with $\dot{\boldsymbol{T}}$ is presented. The dashed curves represent experimental functions which were fitted to the data. The microhardness variations in $\mathrm{Al}-3 \mathrm{wt} . \% \mathrm{Si}$ and $\mathrm{Al}$ -7 wt. $\%$ Si alloys are characterized by 0.14 and 0.18 power laws, respectively. It is worth mentioning that present work highlights the manner by which the microstructure and microhardness (before and after ECAP process) of Al-Si alloys were affected by variation in the cooling rate obtained during the solidification experiments. The finer microstructures resulting from solidification experiments were observed under higher cooling rates. This rapid cooling hinders excessive growth of the microstructures, which favors a finer and even distribution of silicon deposits and also less solute segregation is favored during solidification. These factors, previously discussed, affect the microhardness of the as-cast Al-Si alloys, even after ECAP process, as observed in Figs. 15a and 15b.

\section{Conclusions}

A thorough analysis of our results revealed that the speed of solidification decreases faster in the positions near the water-cooled system and this speed becomes almost constant as moves away from the mold bottom. This behavior is due to an increase in the thermal resistance of the newly solidified 
layers, which hampers heat extraction during solidification experiments.

A deviation between the profiles of solidification speed was observed, which suggests that an increase in silicon concentration in the tested alloys provoked a decrease of $\boldsymbol{S}_{\boldsymbol{S}}$. A similar behavior was noted in the $\dot{\boldsymbol{T}}$ versus $\boldsymbol{P}$ plots, i.e., high values of cooling rate in positions near to mold bottom, followed by a gradual decrease with $\boldsymbol{P}$ in the castings. Comparing, on the other hand, the $\boldsymbol{L}_{\text {st }}$ versus $\boldsymbol{P}$ and $\boldsymbol{S}_{S}$ versus $\boldsymbol{P}$ plots, $\boldsymbol{S}_{S}$ is seen to decrease abruptly at the region close to mold bottom, followed by a gradual decrease along the castings. However, an opposite behavior can be observed for $\boldsymbol{L}_{s t}$, i.e., the thermal parameter increases from the region close to mold bottom. It seems reasonable to surmise that, owing to the amount of silicon added to the alloy being experimented with (from 3 to $7 \mathrm{wt} . \% \mathrm{Si}$ ) in order to operate as a limiting agent on the heat transfer throughout the casting process, the higher Si concentration can affect thermal parameters such as $\boldsymbol{S}_{s}, \dot{\boldsymbol{T}}$ and $\boldsymbol{L}_{s}$.

Post-solidification microhardness was also investigated. Results suggest that higher microhardness values can be obtained by the combined effect of higher $\dot{\boldsymbol{T}}$ and high silicon concentration. Specimens of the as-cast material were submitted to equal channel angular pressing with three passes via route $\boldsymbol{C}$. In these particular experiments, microhardness was favored by the severe plastic deformation process. However, the microhardness profiles of both alloys are clearly nonlinear, both curves tending downwards as one moves away from the mold bottom. The results have pointed out that the cooling rate still exerts a strong effect on the microhardness, even after the as-cast material was submitted to equal-channel angular pressing.

\section{Acknowledgments}

The authors are grateful to FAPERJ (Fundação de Amparo à Pesquisa do Estado do Rio de Janeiro, APQ\#1: E-26/010.001942/2019) and CNPq (Conselho Nacional de Desenvolvimento Científico e Tecnológico, n 305181/20190, PQ - 2019) for financial support.

\section{References}

1. Baptista LAS, Ferreira AF, Paradela KG, Silva DM, Castro JA. Experimental investigation of ternary Al-Si-Cu alloy solidified with unsteady-state heat flow conditions. Mater Res. 2018;21(3):e20170565. http://dx.doi.org/10.1590/1980-5373$\mathrm{mr}-2017-0565$.

2. Ferreira AF, Castro JA, Ferreira LO. Predicting secondary-dendrite arm spacing of the Al- $4.5 \mathrm{wt} \% \mathrm{Cu}$ alloy during unidirectional solidification. Mater Res. 2017;20(1):68-75.

3. Goulart PR, Cruz KS, Spinelli JE, Ferreira IL, Cheung N, Garcia A. Cellular growth during transient directional solidification of hypoeutectic Al-Fe alloys. J Alloys Compd. 2009;470:589-99.

4. Gündüz M, Çardili E. Directional solidification of aluminiumcopper alloys. Mater Sci Eng A. 2002;327:167-85.

5. Silva AP, Spinelli JE, Garcia A. Microstructural evolution during upward and downward transient directional solidification of hypomonotectic and monotectic Al-Bi alloys. J Alloys Compd. 2009;480:485-93.

6. Meza ES, Bertelli F, Goulart PR, Cheung N, Garcia A. The Effect of the growth rate on microsegregation: experimental investigation in hypoeutectic $\mathrm{Al}-\mathrm{Fe}$ and $\mathrm{Al}-\mathrm{Cu}$ alloys directionally solidified. J Alloys Compd. 2013;561:193-200.

7. Avazkonandeh-Gharavol MH, Haddad-Sabzevar M, Fredriksson H. Effect of partition coefficient on microsegregation during solidification of aluminium alloys. Int J Miner Metall Mater. 2014;21(10):980-9

8. Gündüz M, Kaya H, Çardili E, Marasli N, Keslioglu K, Saatçi B. Effect of solidification processing parameters on the cellular spacings in the Al-0.1 wt $\%$ Ti and $\mathrm{Al}-0.5 \mathrm{wt} \% \mathrm{Ti}$ alloys. J Alloys Compd. 2007;439:114-27.

9. Trivedi R, Miyara H, Mazumber P, Simsek E, Tewari SN. Directional solidification microstructure in diffusive and convective regimes. J Cryst Growth. 2001;222(1-2):365-79.

10. Clarke AJ, Tourret D, Imhoff SD, Gibbs PJ, Fezza K, Cooley $\mathrm{JC}$, et al. X-ray imaging and controlled solidification of Al$\mathrm{Cu}$ alloys toward microstructures by design. Adv Eng Mater. 2015;17(4):454-9.

11. Baptista LAS, Paradela KG, Ferreira IL, Garcia A, Ferreira AF. Experimental study of the evolution of tertiary dendritic arms and microsegregation in directionally solidified $\mathrm{Al}-\mathrm{Si}-\mathrm{Cu}$ alloys castings. J Mater Res Technol. 2019;8(1):1515-21.

12. Costa TA, Moreira AL, Moutinho DJ, Dias M, Ferreira IL, Spinelli JE, et al. Growth direction and Si alloying affecting directionally solidified structures of $\mathrm{Al}-\mathrm{Cu}-\mathrm{Si}$ alloys. Mater Sci Technol. 2014;31(9):1103-12. http://dx.doi.org/10.1179/1 743284714Y.0000000678.

13. Rocha OFL, Moutinho DJ, Gomes LG, Ferreira IL, Garcia A. Thermal parameters, microstructure and porosity during transient solidification of ternary Al-Cu-Si alloys. Mater Sci Forum. 2012;730-732:883-8.

14. Ferreira IL, Moutinho DJ, Gomes LG, Rocha OL, Goulart PR, Garcia A. Microstructural development in a ternary Al$\mathrm{Cu}-\mathrm{Si}$ alloy during transient solidification. Mater Sci Forum. 2012;636-637:643-50.

15. Sales RC, Felipe P Jr, Paradela KG, Garção WJL, Ferreira AF. Effect of solidification processing parameters and silicon content on the dendritic spacing and hardness in hypoeutectic Al-Si alloys. Mater Res. 2018;21(6):e20180333. http://dx.doi. org/10.1590/1980-5373-mr-2018-0333.

16. Mathiesen RH, Arbberg L, Bleuet P, Somogyi A. Crystal fragmentation and columnar-to-equiaxed transitions in $\mathrm{Al}-\mathrm{Cu}$ studied by synchrotron X-ray video microscopy. Metall Mater Trans, A Phys Metall Mater Sci. 2006;37(8):2515-24.

17. Ruvalcaba D, Mathiesen RH, Eskin DG, Arnberg L, Katgerman L. In situ observations of dendritic fragmentation due to local solute-enrichment during directional solidification of an aluminum alloy. Acta Mater. 2007;55(13):4287-92.

18. Spinelli JE, Rocha OFL, Garcia A. The influence of melt convection on dendritic spacing of downward unsteady-state directionally solidified Sn-Pb alloys. Mater Res. 2006;9(1):51-7.

19. Arab SM, Akbarzadeh A. The effect of equal channel angular pressing process on the microstructure of AZ31 Mg alloy strip shaped specimens. J Magnes Alloy. 2013;1:145-9.

20. Chegini M, Fallahi A, Shaeri MH. Effect of equal channel angular pressing (ECAP) on wear behavior of Al-7075 alloy. Procedia Mater Sci. 2015;11:95-110.

21. Qarni MJ, Sivaswamy G, Rososhowski A, Bockal S. Effect of incremental equal channel angular pressing (I-ECAP) on the microstructural characteristics and mechanical behavior of commercially pure titanium. Mater Des. 2017;122:385-402.

22. Huang Y, Landon TG. Advances in ultrafine-grained materials. Mater Today. 2013;16(3):85-93.

23. Duan ZC, Langdon TG. An experimental evaluation of a special ECAP die containing two equal arcs of curvature. Mater Sci Eng A. 2011;528A:4173-9.

24. García-Infanta JM, Zhilyaev AP, Cepeda-Jiménez CM, Ruano OA, Carreño F. Effect of the deformation path on the ductility of a hypoeutectic Al-Si casting alloy subjected to equal-channel 
angular pressing by routes A, BA, BC and C. Scr Mater. 2008;58:138-41.

25. García-Infanta JM, Swaminathan S, Zhilyaev AP, Carreño F, Ruano OA, McNelley TR. Microstructural development during equal channel angular pressing of hypo-eutectic $\mathrm{Al}-\mathrm{Si}$ casting alloy by different processing routes. Mater Sci Eng A. 2008;485:160-75.

26. Swaminathan S, García-Infanta JM, McNelley TR, Ruano OA, Carreño F. Severe plastic deformation of an as-cast hypoeutectic Al-Si alloy. J Mater Sci. 2008;43:7501-6.

27. Ferreira AF, Chrisóstimo WB, Sales RC, Garção WJL, Sousa NP. Effect of pouring temperature on microstructure and microsegregation of as-cast aluminum alloy. Int J Adv Manuf Technol. 2019;104(1-4):957-65.

28. Junior PF. Experimental and numerical analysis of the columnar to equiaxed transition in unidirectional solidification of aluminium binary alloys under transient conditions of heat extraction [unpublished thesis]. Rio de Janeiro: Universidade Federal Fluminense; 2019.

29. Paradela KG, Baptista LAS, Sales RC, Felipe PF Jr, Ferreira AF. Investigation of thermal parameters effects on the microstructure, microhardness and microsegregation of $\mathrm{Cu}-\mathrm{Sn}$ alloy directionally solidified under transient heat flow conditions. Mater Res. 2019;22(4):e20190259. http://dx.doi.org/10.1590/1980-5373MR-2019-0259.

30. Garcia A. Solidification: fundamentals and applications. Campinas: Editora Unicamp; 2007.

31. Nakashima K, Horita Z, Nemoyo M, Langdon TG. Development of a multi-pass facility for equal-channel angular pressing to high total strains. Mater Sci Eng A. 2000;281:82-7.

32. Furukawa M, Iwahashi Y, Horita Z, Nemoyo M, Langdon TG. The shearing characteristics associated with equal-channel angular pressing. Mater Sci Eng A. 1998;257:328-32.

33. Thermo-Calc Software. Thermo-Calc Software AB. Sweden: Thermo-Calc Software; 2020.

34. Sá F, Rocha OL, Siqueira CA, Garcia A. The effect of solidification variables on tertiary dendrite arm spacing in unsteady-state directional solidification of $\mathrm{Sn}-\mathrm{Pb}$ and $\mathrm{Al}-\mathrm{Cu}$ alloys. Mater Sci Eng A. 2004;373:131-8.

35. Carvalho D, Rodrigues J, Soares D, Aviz J, Barros A, Silva $\mathrm{M}$, et al. Microindentation hardness-secondary dendritic spacings correlation with casting thermal parameters in an Al-9wt.\% $\% \mathrm{Si}$ alloy. Mater Sci. 2018;24(1):18-23.

36. Haghshenas M, Zarei-Hanzaki A, Sabetghadam H. The room temperature mechanical properties of a thermo-mechanically processed thixocast A356 aluminum alloy. J Alloys Compd. 2009;477:250-5. 